\title{
BMJ Burnout levels among Portuguese family Open doctors: a nationwide survey
}

To cite: Marcelino G, Cerveira JM, Carvalho I, et al. Burnout levels among Portuguese family doctors: a nationwide survey. BMJ Open 2012;2:e001050. doi:10.1136/

bmjopen-2012-001050

- Prepublication history and additional figure and tables for this paper are available online. To view these files please visit the journal online (http://dx.doi.org/10.1136/ bmjopen-2012-001050).

GM and JM-C contributed equally.

Received 20 February 2012 Accepted 3 May 2012

This final article is available for use under the terms of the Creative Commons Attribution Non-Commercial 2.0 Licence; see http://bmjopen.bmj.com

${ }^{1}$ Medical Faculty of Lisbon, University of Lisbon, Lisbon, Portugal

${ }^{2}$ Park Family Healthcare Unit, Alvalade Health Center, Lisbon, Portugal ${ }^{3}$ Institute of Social and Preventive Medicine (IUMSP), University Hospital of Lausanne, Lausanne, Switzerland

Correspondence to Gisela Teodoro Marcelino; giselamarcelino@sapo.pt

Gisela Marcelino, ${ }^{1}$ João Melich Cerveira, ${ }^{1}$ Inês Carvalho, ${ }^{1}$ João Azeredo Costa, ${ }^{1}$ Marta Lopes, ${ }^{1}$ Nelson Encarnação Calado, ${ }^{2}$ Pedro Marques-Vidal ${ }^{3}$

\section{ABSTRACT}

Aim: To characterise the prevalence of burnout syndrome in a sample of family doctors (FDs) working in the Portuguese National Health System.

Design: Cross-sectional survey.

Setting: Primary healthcare centres from the 18 continental districts and two archipelagos of Portugal. Method: The Portuguese version of the Maslach Burnout Inventory - Human Services Survey was sent to 40 randomly selected healthcare centres and distributed to the FDs employed. Socio-demographic and work-related data were also collected. Participants were classified as having high, average or low levels of emotional exhaustion (EE), depersonalisation (DP) and personal accomplishment (PA) dimensions of burnout. Results: 371 questionnaires were sent, of which 153 (83 women, age range 29-64 years; response rate $41 \%)$ returned. One-quarter $(25.3 \%, 95 \% \mathrm{Cl} 18.6 \%$ to $33.1 \%)$ of FDs scored high for EE, $16.2 \%(10.7 \%$ to $23.2 \%)$ for DP and $16.7 \%$ (11.1\% to $23.6 \%$ ) for lack of PA. On multivariate analysis, being married, of older age, having many years of practice or working in a personalised healthcare unit tended to be associated with increased burnout components. Men tended to present higher EE and DP but lower lack of PA than women. Finally, the prevalence $(95 \% \mathrm{Cl})$ of burnout ranged between $4.1 \%(1.5 \%$ to $8.6 \%)$ and $32.4 \%$ $(25.0 \%$ to $40.6 \%)$, depending on the definition used. Conclusions: High burnout is relatively common among Portuguese FDs. Burnout relief measures should be developed in order to prevent a further increase of burnout syndrome among Portuguese FDs.

\section{INTRODUCTION}

In the last 3 decades, burnout syndrome increased to worrisome levels in doctors, ${ }^{12}$ including family doctors (FDs). ${ }^{3}$ Despite the presence of burnout, most FDs usually do not seek help, ${ }^{4}$ which might lead to a decrease in their performance and even compromise adequate treatment of patients.

Burnout is consequent to job-related chronic stress $^{5}$ and is characterised by a symptomatic triad of emotional exhaustion (EE) (feelings of tiredness and emptiness), depersonalisation (DP) (empathy disappear-

\section{ARTICLE SUMMARY}

Article focus

- In the last 3 decades, burnout syndrome increased to worrisome levels in doctors, including FDs, and there are scarce data concerning this condition in Portuguese FDs.

Key messages

- The prevalence $(95 \% \mathrm{Cl})$ of burnout ranged between $4.1 \%(1.5 \%$ to $8.6 \%)$ and $32.4 \%$ $(25.0 \%$ to $40.6 \%)$, depending on the definition used.

Strengths and limitations of this study

- First study assessing burnout among Portuguese FDs using a stratified random sample. The limitations of the study include the relatively low participation rate (but comparable to other similar studies) and the fact that the Portuguese version of the Maslach Burnout InventoryHuman Services Survey questionnaire has not been validated. Still, Cronbach's $\alpha$ values ranged between 0.64 (for DP) and 0.90 (for $\mathrm{EE}$ ), in agreement with the literature.

ance, cynicism and automatism) and a lack of personal accomplishment (PA) (lack of self-esteem and frustration). ${ }^{5}$

In 2008, a European study on burnout among European FDs (the EGPRN study ${ }^{3}$ ) showed that $43 \%$ of respondents scored high for EE burnout, $35 \%$ for DP and $32 \%$ for PA, with $12 \%$ scoring high burnout in all three dimensions. Unfortunately, the EGPRN study did not include Portugal, so we conducted a study to assess the prevalence of burnout among Portuguese FDs, using the same methodology as the EGPRN.

\section{METHODS}

\section{Sampling}

This study was conducted between November 2010 and November 2011. A stratified and randomised sampling was conducted selecting two primary healthcare centres (HCCs) from each of the 18 Portuguese 
continental districts and two archipelagos (Madeira and Azores) of Portugal as described in the site 'Portal da Saúde' from the Portuguese Ministry of Health. ${ }^{6}$ The districts and archipelagos constituted the strata and each primary HCC was considered as a cluster. Questionnaires were sent with pre-paid return envelopes to previously contacted HCC employees, who distributed the questionnaires with informed consent to every FD employed. Seventeen questionnaires were sent and received via email.

FDs in HCCs work in either family healthcare units (FHCUs) or personalised healthcare units (PHCUs). Beyond their organisational differences, the first provides healthcare to families, which have a FD, while the second one provides healthcare to those who have a FD and also to individuals who do not have a FD.

The study was approved by the Ethics Commissions of North, Algarve and Madeira and also by all corresponding Portuguese Regional Administrations.

\section{Burnout}

Burnout was assessed using the Portuguese translation of the Maslach Burnout Inventory-Human Services Survey (MBI-HSS). ${ }^{4}$ Answers to the MBI-HSS were used to classify the participants as having high, average or low levels in EE, DP and PA dimensions of burnout. In agreement with a previous study, ${ }^{3}$ the following cut-offs were used to define low, average or high levels of each dimension of the MBI-HSS-EE: low, $\leq 13$; average, 14-26; high, $\geq 27$; DP: low, $\leq 5$; average, $6-9$; high, $\geq 10$; PA: low, $\leq 33$; average, $32-39$; high, $\geq 40$ (inverse scale). ${ }^{3}$ As the definition of burnout is a controversial subject, we applied different definitions as described in the literature: (1) high levels of EE and DP combined with low PA (C Maslach, personal communication, 2008) ${ }^{7}$; (2) high $\mathrm{EE}$ and/or high $\mathrm{DP}^{89}$ and (3) high negative score on EE in combination with high DP or low PA. ${ }^{10}$ As to missing data, for each skipped MBI-HSS item, it was attributed the mean score calculated for that question's dimension. Two skipped questions were coded as missing value for the whole dimension. Two answers for the same item were coded as one skipped question and replaced by the average of that dimension.

Data regarding socio-demographic and work-related questions were also collected.

\section{Statistical analysis}

Statistical analysis was performed using SPSS V.19.0 (IBM SPSS statistics). Results were expressed as median (interquartile interval), mean $\pm \mathrm{SD}$ or number of subjects (percentage). Bivariate comparisons were performed using Mann-Whitney or Kruskal-Wallis non-parametric tests for quantitative data and by $\chi^{2}$ for qualitative data. Multivariate analysis was conducted using SPSS complex samples logistic regression analysis stratifying samples by district/archipelago and including as main effects all variables which reached an $\alpha$ level of at least 0.25 . Conversely, we did not take into account the clustering as for many health centres the number of participants was very low $(<3)$. Results were considered significant if $\mathrm{p}<0.05$.

\section{RESULTS}

Overall, 371 questionnaires were sent, of which 153 (response rate $41 \%$ ) were retrieved. From these, only 150 were considered valid for the analysis. No information could be obtained regarding the socio-demographic characteristics of non-responders.

The main results are summarised in tables 1 and 2 . Men were older and had more years of professional activity than women. Overall, $25.3 \%$ (95\% CI $18.6 \%$ to $33.1 \%$ ) of participants scored high for EE, $16.2 \%$ ( $10.7 \%$ to $23.2 \%)$ for DP and $16.7 \%$ ( $11.1 \%$ to $23.6 \%)$ for low PA; $2.0 \%$ scored high for all three dimensions. Men had higher DP and PA scores than women, while no differences were found for EE (table 1).

No significant bivariate association was found between burnout components and most participants' characteristics (table 2), with the exception of marital status, and

Table 1 Main characteristics of the participants

\begin{tabular}{|c|c|c|c|c|}
\hline Variables & All & Men & Women & Test \\
\hline \multirow[t]{2}{*}{ Age } & $54.5(9.0)$ & $55.0(5.0)$ & $53.0(13.0)$ & $1813.0^{\star * *}$ \\
\hline & $n=148$ & $\mathrm{n}=67$ & $\mathrm{n}=81$ & \\
\hline \multirow[t]{2}{*}{ Years of professional activity } & $29.0(10.3)$ & $30.0(4.0)$ & $28.0(5.0)$ & $2103.0^{*}$ \\
\hline & $n=150$ & $n=67$ & $\mathrm{n}=83$ & \\
\hline \multirow[t]{2}{*}{ Hours of work per week } & $42.0(3.0)$ & $42.0(3.4)$ & $42.0(2.0)$ & $2744.0^{\mathrm{ns}}$ \\
\hline & $n=150$ & $n=68$ & $\mathrm{n}=82$ & \\
\hline \multirow[t]{2}{*}{ Hours of contact with patients per day } & $7.0(1.5)$ & $7.0(1.6)$ & $7.0(1.6)$ & $2201.0^{\mathrm{ns}}$ \\
\hline & $n=138$ & $\mathrm{n}=61$ & $\mathrm{n}=77$ & \\
\hline Emotional exhaustion score & $16.0(19.0)$ & $17.0(22.0)$ & $14.5(16.3)$ & $2584.5^{\mathrm{ns}}$ \\
\hline Depersonalisation score & $4.0(5.0)$ & $6.0(6.8)$ & $3.0(5.8)$ & $2078.0^{*}$ \\
\hline Personal accomplishment score & $41.0(8.0)$ & $42.5(8.0)$ & $40.0(8.0)$ & $2206.0^{*}$ \\
\hline
\end{tabular}


Table 2 Prevalence of burnout components according to selected participants' characteristics

\begin{tabular}{|c|c|c|c|c|c|c|}
\hline & $\begin{array}{l}\text { Emotional } \\
\text { exhaustion }\end{array}$ & $\begin{array}{l}\text { Test } \\
\text { ( } p \text { value) }\end{array}$ & Depersonalisation & $\begin{array}{l}\text { Test } \\
\text { (p value) }\end{array}$ & $\begin{array}{l}\text { Personal } \\
\text { accomplishment }\end{array}$ & $\begin{array}{l}\text { Test } \\
\text { ( } p \text { value) }\end{array}$ \\
\hline \multicolumn{7}{|l|}{ Gender } \\
\hline Man & 30.9 (20.2 to 43.3$)$ & \multirow[t]{2}{*}{$2.03(0.16)$} & 22.1 (12.9 to 33.8$)$ & \multirow[t]{2}{*}{$3.16(0.08)$} & 11.8 (5.2 to 21.9 ) & \multirow[t]{2}{*}{$2.15(0.14)$} \\
\hline Woman & 20.7 (12.6 to 31.1$)$ & & 11.3 (5.3 to 20.3$)$ & & 20.7 (12.6 to 31.1$)$ & \\
\hline \multicolumn{7}{|l|}{ Age (years) } \\
\hline$\leq 45$ & 22.6 (9.6 to 41.1$)$ & \multirow[t]{2}{*}{$0.14(0.71)$} & 9.7 (2.0 to 25.8 ) & \multirow[t]{2}{*}{$1.13(0.29)$} & $6.5(0.1$ to 21.4$)$ & \multirow[t]{2}{*}{$2.52(0.11)$} \\
\hline$>45$ & 25.9 (18.2 to 34.8$)$ & & 17.5 (11.1 to 25.8$)$ & & 18.1 (11.6 to 26.3$)$ & \\
\hline \multicolumn{7}{|l|}{ Children } \\
\hline Yes & 13.3 (1.7 to 40.5$)$ & \multirow[t]{2}{*}{$1.27(0.26)$} & 6.7 (0.2 to 31.9$)$ & \multirow[t]{2}{*}{$0.47 \S$} & 26.7 (7.8 to 55.1$)$ & \multirow[t]{2}{*}{$0.28 \S$} \\
\hline No & 26.7 (19.4 to 35.0$)$ & & 17.3 (11.3 to 24.8$)$ & & 15.6 (9.9 to 22.8$)$ & \\
\hline \multicolumn{7}{|l|}{ Marital status } \\
\hline Single/divorced & 11.8 (3.3 to 27.5 ) & \multirow[t]{2}{*}{$4.12(0.04)$} & $6.1(0.1$ to 20.2$)$ & \multirow[t]{2}{*}{$3.02(0.08)$} & 17.6 (6.8 to 34.5$)$ & \multirow[t]{2}{*}{$0.02(0.89)$} \\
\hline Married/union & 28.9 (20.8 to 38.2$)$ & & 18.6 (11.9 to 27.0$)$ & & $16.7(10.3$ to 24.8$)$ & \\
\hline \multicolumn{7}{|l|}{ Practice years } \\
\hline$\leq 20$ & 19.4 (8.2 to 36.0$)$ & \multirow[t]{2}{*}{$0.82(0.34)$} & 8.3 (1.8 to 22.5 ) & \multirow[t]{2}{*}{$2.23(0.14)$} & 8.3 (1.8 to 22.5 ) & \multirow[t]{2}{*}{$2.43(0.12)$} \\
\hline$>20$ & 27.4 (19.5 to 36.6$)$ & & $18.9(12.1$ to 27.5$)$ & & 19.5 (12.6 to 27.8$)$ & \\
\hline \multicolumn{7}{|l|}{ Hours/day patient } \\
\hline$\leq 7$ & 25.6 (16.4 to 37.8$)$ & \multirow[t]{2}{*}{$0.04(0.85)$} & $19.2(11.1$ to 29.7$)$ & \multirow[t]{2}{*}{$0.70(0.40)$} & 15.4 (8.2 to 25.3 ) & \multirow[t]{2}{*}{$0.26(0.61)$} \\
\hline$>7$ & 27.1 (16.4 to 40.3$)$ & & $13.8(6.1$ to 25.4$)$ & & 18.6 (9.7 to 30.9$)$ & \\
\hline \multicolumn{7}{|l|}{ Hours/week inst. } \\
\hline$\leq 40$ & 25.0 (14.7 to 37.9$)$ & \multirow[t]{2}{*}{$0.01(0.91)$} & 16.7 (8.3 to 28.5$)$ & \multirow[t]{2}{*}{$0.01(0.93)$} & $18.3(9.5$ to 30.4$)$ & \multirow[t]{2}{*}{$0.17(0.68)$} \\
\hline$>40$ & 25.8 (17.1 to 36.2$)$ & & 16.1 (9.1 to 25.5$)$ & & 15.7 (8.9 to 25.0$)$ & \\
\hline \multicolumn{7}{|l|}{ Practice unit } \\
\hline FHCU & 16.3 (6.8 to 30.7$)$ & \multirow[t]{2}{*}{$1.92(0.17)$} & 18.6 (8.4 to 33.4$)$ & \multirow[t]{2}{*}{$0.41(0.52)$} & 9.3 (2.6 to 22.1$)$ & \multirow[t]{2}{*}{$2.26(0.13)$} \\
\hline PHCU & 27.2 (18.4 to 37.4$)$ & & 14.3 (7.8 to 23.2 ) & & 19.6 (12.0 to 29.1$)$ & \\
\hline Other inst. & & & & & & \\
\hline Yes & 24.7 (16.5 to 34.5$)$ & $0.01(0.92)$ & 15.6 (9.0 to 24.5$)$ & $0.01(0.95)$ & 17.5 (10.6 to 26.6$)$ & $0.08(0.78)$ \\
\hline No & 25.5 (14.3 to 39.6$)$ & & 16.0 (7.2 to 29.1$)$ & & 15.7 (7.0 to 28.6$)$ & \\
\hline
\end{tabular}

similar findings were obtained when mean scores were computed, although men presented higher DP and PA scores than women (supplementary table 1).

The number of participants with low, average and high burnout scores in none, one, two or three subscales is summarised in table 3 and in figure 1 . The prevalence (95\% CI) of burnout among Portuguese FDs was $4.1 \%$ ( $1.5 \%$ to $8.6 \%)$ for definition $1,32.4 \%(25.0 \%$ to $40.6 \%)$ for definition 2 and $13.5 \%$ (8.5\% to $20.1 \%)$ for definition 3.

Multivariate logistic regression was conducted separately for each burnout component taking into account stratification and including all variables, which were associated at $p<0.025$. The results are summarised in table 4. Men showed a lower likelihood of presenting with low PA. Conversely, no other variable was significantly associated with burnout components, although positive (deleterious) trends were found for male sex (high EE and DP), being married (high EE and DP), older age (high PA), increased years of activity (high DP and low PA) and working in a PHCU (high EE and low PA). Similar findings were obtained when the analysis was conducted without taking into account sample stratification (supplementary table 2).

Table 3 Number of participants with low, average and high burnout scores in none, one, two or three subscales

\begin{tabular}{|c|c|c|c|c|c|}
\hline & \multicolumn{4}{|c|}{ High burnout } & \multirow[b]{2}{*}{ Total } \\
\hline & 0 & 1 & 2 & 3 & \\
\hline \multicolumn{6}{|c|}{ Average burnout } \\
\hline 0 & $29(19.6)$ & $13(8.8)$ & $6(4.1)$ & $6(4.1)$ & $54(36.5)$ \\
\hline 1 & $42(28.4)$ & $16(10.8)$ & $10(6.8)$ & - & $68(45.9)$ \\
\hline 2 & $15(10.1)$ & $7(4.7)$ & - & - & $22(14.9)$ \\
\hline 3 & $4(2.7)$ & - & - & - & $4(2.7)$ \\
\hline Total & $90(60.8)$ & $36(24.3)$ & $16(10.8)$ & $6(4.1)$ & $148(100.0)$ \\
\hline
\end{tabular}

The possible combinations for the different subscales describing increasing burnout are shown in the table. Participants with low burnout scores in one dimension are represented by excluding average or high burnout. Results are expressed as number (percentage) of the total subjects. 


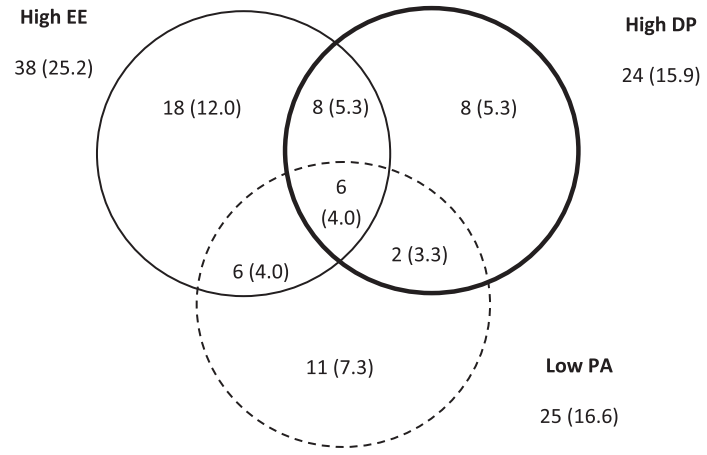

Figure 1 Venn's diagram with the number of participants with high burnout scores in one, two or three subscales, $N=150$. Results are expressed as number (percentage) of subjects. DP, depersonalisation; EE, emotional exhaustion; PA, personal accomplishment.

Table 5 compares the results of the current study with those reported from other countries. Overall, Portuguese FDs tended to present a lower prevalence of burnout components than in other countries.

\section{DISCUSSION}

To our knowledge, this is the first study ever to assess rates of burnout among FDs in Portugal. Our study also complements the previous findings of the EGPRN study, ${ }^{3}$ which assessed burnout among FDs from 12 European countries. Our results suggest that Portuguese FDs tend to present lower burnout levels for the three subscales EE, DP and PA than in other European countries.

Although men scored higher than women, no significant difference was found regarding the prevalence of high EE, high DP or low PA between genders. Still, multivariate analysis showed that men had a lower likelihood of presenting with low PA after adjusting for years of activity, and a similar trend was found after adjusting for age. Conversely, men tended to present higher levels of EE and DP than women, and this trend persisted after multivariate adjustment. Overall, our results suggest that Portuguese male FDs are more likely to present with EE or DP than their female colleagues but that they feel more accomplished than women FDs. A possible explanation might be the greater female involvement with family and home organisation in comparison to men, since having children has been regarded as protective for burnout development, ${ }^{3}{ }^{4}$ and that little time for family contact and support increases its risk. ${ }^{5}$ Many other recent studies regarding burnout on FDs have also found higher burnout trends among men FDs. ${ }^{3}{ }^{12}{ }^{13}$ Still, further investigation is warranted as different results and possible explanations have been described. ${ }^{14}$

Married or cohabitating FDs tended to present higher EE and DP than single colleagues. Still, having children was not associated with burnout components. These two findings compromise the hypothesis of the family workload as a factor of stress. Another possible explanation might be related to increased marital problems among Portuguese FDs since it is known that FDs who have marital problems tend to have negative emotional and behavioural changes. ${ }^{5}$

Older age (and also longer time of practice) tended to be associated with higher levels of burnout components. The responsibility of a FD within a HCC is no longer related to age due to medical career freezing for more than 14 years now. ${ }^{15}$ Moreover, burnout is described to be more common among younger FDs, ${ }^{3} 14$ so a possible hypothesis for these results might be a greater incidence of other clinical syndromes among older FDs and that

Table 4 Logistic regression to assess the factors individually and independently associated with burnout components

\begin{tabular}{|c|c|c|c|c|}
\hline & High EE & High DP & Low PA (1) & Low PA (2) \\
\hline \multicolumn{5}{|l|}{ Gender } \\
\hline Female & 1 (ref.) & 1 (ref.) & 1 (ref.) & 1 (ref.) \\
\hline Male & 1.45 (0.63 to 3.43$)$ & $2.06(0.82$ to 5.21$)$ & $0.40(0.14$ to 1.13$)$ & $0.33(0.12$ to 0.93$)$ \\
\hline \multicolumn{5}{|l|}{ Marital status } \\
\hline Single/divorced & 1 (ref.) & 1 (ref.) & - & - \\
\hline Married/union & 3.06 (0.83 to 11.23$)$ & $2.88(0.59$ to 14.04$)$ & - & - \\
\hline \multicolumn{5}{|l|}{ Age category } \\
\hline$\leq 45$ & - & - & 1 (ref.) & - \\
\hline$>45$ & - & - & 3.31 (0.71 to 15.5$)$ & - \\
\hline \multicolumn{5}{|l|}{ Years of activity } \\
\hline$\leq 20$ & - & 1 (ref.) & - & 1 (ref.) \\
\hline$>20$ & - & $1.78(0.48$ to 6.61$)$ & - & 3.07 (0.84 to 11.22$)$ \\
\hline \multicolumn{5}{|l|}{ Practice unit } \\
\hline FHCU & 1 (ref.) & - & 1 (ref.) & 1 (ref.) \\
\hline $\mathrm{PHCU}$ & 2.48 (0.89 to 6.93$)$ & - & $3.02(0.82$ to 11.18$)$ & 2.63 (0.83 to 8.38 ) \\
\hline
\end{tabular}

Results are expressed as OR $(95 \% \mathrm{Cl})$. For PA, two models were used as the variables years of activity and age categories were correlated and their simultaneous inclusion led to a non-estimable model. Statistical analysis by multivariate logistic regression taking into account sample stratification.

-, not included in the model; DP, depersonalisation; EE, emotional exhaustion; FHCU, family healthcare unit; PA, personal accomplishment; $\mathrm{PHCU}$, personalised healthcare unit. 
Table 5 Results for each burnout subscale in previous and recent European studies

\begin{tabular}{|c|c|c|c|}
\hline European studies & EE & DP & PA \\
\hline EGPRN study, overall $(2008, n=1393)^{3}$ & $24.0 \pm 16.0$ & $7.0 \pm 7.0$ & $37.0 \pm 11.0$ \\
\hline Spanish FDs* $(2005, n=86)^{11}$ & $21.0(16.8-29.5)$ & $21.0(3.0-12.0)$ & $39.0(33.0-39.0)$ \\
\hline Swiss FDs $(2005, n=1584)^{12}$ & $17.0(10.0-24.0)$ & $6.0(3.0-9.0)$ & $41.0(36.0-45.0)$ \\
\hline Portugal (this study) $(n=150)$ & $16.0(8.0-27.0)$ & $4.0(2.0-7.0)$ & $41.0(36.0-44.0)$ \\
\hline EGPRN study $(2008)^{3}$ & High EE (\%, 99\% Cl) & High DP $(\%, 99 \% \mathrm{Cl})$ & Low PA (\%, 99\% Cl) \\
\hline Overall $(n=1393)$ & $43.0(40.5$ to 45.6$)$ & 35.3 (32.9 to 37.9$)$ & 32.0 (29.6 to 34.5$)$ \\
\hline Bulgaria $(n=69)$ & $62.3(50.5$ to 72.8$)$ & 30.4 (20.8 to 42.1$)$ & $18.8(14.4$ to 29.6$)$ \\
\hline Croatia $(n=117)$ & 41.9 (33.3 to 50.9$)$ & $12.0(7.3$ to 19.1$)$ & 13.7 (8.6 to 21.1$)$ \\
\hline France $(n=178)$ & 33.7 (27.2 to 40.9$)$ & 35.4 (28.7 to 42.7$)$ & $27.5(21.5$ to 34.5$)$ \\
\hline Greece $(n=45)$ & 31.8 (20.0 to 46.6$)$ & 73.3 (59.0 to 84.0$)$ & 93.2 (81.8 to 97.7$)$ \\
\hline Hungary $(n=87)$ & 36.8 (27.4 to 47.3$)$ & 35.6 (26.4 to 46.1$)$ & 26.4 (18.3 to 36.6$)$ \\
\hline Italy $(n=147)$ & $68.0(60.1$ to 75.0$)$ & 55.1 (47.0 to 62.9$)$ & 40.8 (33.2 to 48.9$)$ \\
\hline Malta $(n=129)$ & 36.4 (28.6 to 45.0$)$ & 31.0 (23.7 to 39.4$)$ & $24.8(18.2$ to 32.9$)$ \\
\hline Poland $(n=150)$ & 48.0 (40.2 to 55.9$)$ & 34.0 (26.9 to 41.9$)$ & 30.0 (23.2 to 37.8$)$ \\
\hline Spain $(n=86)$ & 30.2 (21.5 to 40.6$)$ & 34.9 (25.7 to 45.4$)$ & 25.6 (17.5 to 35.7$)$ \\
\hline Sweden $(n=109)$ & 45.9 (36.8 to 55.2$)$ & 34.9 (26.6 to 44.2$)$ & 11.9 (7.1 to 19.3$)$ \\
\hline Turkey $(n=112)$ & $15.2(9.7$ to 23.0$)$ & $15.2(9.7$ to 23.0$)$ & 69.4 (60.3 to 77.2$)$ \\
\hline England $(n=164)$ & 54.3 (46.6 to 61.7$)$ & 44.5 (37.1 to 52.2$)$ & 32.9 (26.2 to 40.4$)$ \\
\hline Portugal (this study) $(n=150)$ & 25.3 (16.7 to 35.5$)$ & $16.2(9.3$ to 25.4$)$ & 16.7 (9.7 to 25.7$)$ \\
\hline
\end{tabular}

can contribute to exhaustion, ${ }^{4}$ like depression, empty nest syndrome and middle age crisis.

The prevalence of burnout ranged from $4.1 \%$ to $32.4 \%$, depending on the definition used. This wide range is due to the different combinations of EE, DP and PA subscales, as indicated in figure 1. Furthermore, the cut-offs used were those reported in the EGPRN study, ${ }^{3}$ which differ slightly from the cut-offs provided in the 'original' version of the MBI-HSS. ${ }^{16}$ This was done in order to compare our results with those from the literature. Still, using the cut-offs of the 'original' version led to similar conclusions (supplementary tables 3 and 4). Hence, it would be of interest that future studies on burnout report their results using one or several definitions and state the cut-offs used to facilitate comparisons.

Our results also show that working in PHCUs was related to higher burnout levels. This can be explained by the recent transfer of FDs to FHCUs from PHCUs that could have increased workload in PHCUs. Furthermore, the Portuguese Ministry of Health shows interest in transforming PHCUs into FHCUs, a fact that may leave PHCUs financially discriminated. Finally, teamwork is better established in FHCUs, and FDs in these units have more autonomy regarding schedules and clinical practice decisions - a burnout preventing trait. ${ }^{4} 5$

Portuguese FDs tended to present lower burnout scores and also lower prevalence of burnout components than FDs from other European countries (see table 5). A possible explanation might be related to a slightly lower workload among Portuguese FDs compared with their colleagues from other countries. For instance, Portugal has 198.3 FDs per 100000 inhabitants, a much higher number in comparison with the UK, which only has 78.3 FDs per $100000 .{ }^{17}$ Furthermore, a Portuguese FD has on average $1500^{18}$ patients, again a value lower than in the UK (1800). ${ }^{19}$ Still, further studies are advisable to better understand the lower burnout prevalence and scores among Portuguese doctors relative to their European counterparts.

This study has some limitations worth noting. First the response rate $(41 \%)$ was rather low but identical to the one reported by the EGPRN study. ${ }^{3}$ Neither the Portuguese version of the MBI-HSS nor the questionnaire used to measure demographic variables were formally validated, although we are relatively confident that the responses related to demographic variables were adequately provided by the participants. Still, it would be of interest to validate the MBI-HSS so that future studies can rely upon an adequate instrument; still, Cronbach's $\alpha$ values ranged between 0.64 (for DP) and 0.90 (for EE), also in agreement with those reported in the EGPRN study. ${ }^{3}$ A pre-study sample size analysis indicated that a minimum sample size of 384 responders was necessary to achieve an absolute precision of 0.05 for the prevalence rates. Unfortunately, this sample size could not be obtained due to a low response rate. Furthermore, for logistic and financial reasons, it was not possible to send more questionnaires or to sample more health centres. Hence, it is likely that this study is underpowered to detect associations between burnout and the demographic variables studied. Still, it provides the first estimation of burnout syndrome among Portuguese doctors, and it would be of interest to confirm these findings by a larger adequately powered study. Finally, 
only FDs present at the HCCs answered, thus excluding those on sick leave; hence, it is possible that the burnout rates reported are underestimated. Still, in the absence of other studies available, our results provide the first estimation of the burnout rates among FDs in Portugal.

The results of our study have important implications. In Portugal, there is currently no aid for dealing with burnout among health professionals. Hence, it would be of uttermost importance that the Portuguese Ministry of Health, the Portuguese College of Physicians or the Regional Health Administrations provide some support at institutional and individual levels. Finally, another study would be desirable to assess the progression of burnout among Portuguese FDs.

In summary, our results suggest that a significant percentage of Portuguese FDs present with burnout and that male gender, older age and being married tend to increase burnout. These values are nevertheless lower than reported in other European countries.

Acknowledgements We would like to deeply thank the doctors, nurses and secretaries employed in the following HCCs: Aljezur, Alvalade, Barcelos, Benfica, Borba, Castro Daire, Celorico de Bastos, Coruche, Crato, Elvas, Foz do Douro, Francisco Jardim, Gouveia, Grândola, Guarda, Ílhavo, Jardim do Mar, Lousã, Mangualde, Marco de Canaveses, Marinha Grande, Mação, Miranda do Douro, Moita, Odemira, Paredes de Coura, Penamacor, Peso da Régua, Pombal, Ponte da Barca, Proença-a-Nova, Ribeira Grande, Santa Cruz da Graciosa, Tavira, Vagos, Viana do Alentejo, Vidigueira, Vila Nova de Poiares, Vila Pouca de Aguiar and Vimioso.

Contributors We state that GM and JM-C have contributed equally, were responsible for the conception, design and acquisition of data. They both performed the statistical analysis and wrote the article. We also state that PM-V was the tutor of this research study and wrote part of the article. IC, JAC and $M L$ helped with the acquisition of data and, along with NC, scientifically reviewed the paper and made major modifications regarding intellectual content. All authors have given their final approval of the version to be submitted.

Funding The research received no specific grant from any funding agency in the public, commercial or not-for-profit sectors.

Competing interests None.

Patient consent Obtained.
Ethics approval Ethics approval was provided by the Ethics Commissions of North, Algarve and Madeira and also by all corresponding Portuguese Regional Administrations.

Provenance and peer review Not commissioned; externally peer reviewed.

Data sharing statement We state that the manuscript, including related data, figures and tables, has not been previously published, that the manuscript is not under consideration elsewhere and that there are no additional data available.

\section{REFERENCES}

1. Devi S. Doctors in distress. Lancet 2011;377:454-5.

2. Monn MA. Mindfulness Program Staves Off Primary Care Burnout. Family Practice News 2009.

3. Soler JK, Yaman H, Esteva M, et al. Burnout in European family doctors: the EGPRN study. Fam Pract 2008;25:245-65.

4. Delbrouck M. Síndrome de Exaustão (Burnout). 2006. Climepsi ed.

5. de Valk M, Oostrom C. Burnout in the medical profession - causes, consequences and solutions. Occup Health Work 2007;3:1-5.

6. Portuguese Ministry of Health. Portal da Saúde. 2010. http://www. portaldasaude.pt/portal

7. Legassie J, Zibrowski EM, Goldszmidt MA. Measuring resident wellbeing: impostorism and burnout syndrome in residency. $J$ Gen Intern Med 2008:23:1090-4

8. Thomas NK. Resident burnout. JAMA 2004;292:2880-9.

9. Schaufeli W, Bakker A, Hoogduin $\mathrm{K}$, et al. On the clinical validity of the Maslach burnout inventory and the burnout measure. Psychol Health 2001;16:565-82.

10. Brenninkmeijer V, VanYperen N. How to conduct research on burnout: advantages and disadvantages of a unidimensional approach in burnout research. Occup Environ Med 2003;60:i16-20.

11. Esteva M, Larraz C, Soler J, et al. Burn-out in Spanish general practitioners. Aten Primaria 2005;35:108-9.

12. Goehring $\mathrm{C}$, Bouvier Gallacchi M, Künzi B, et al. Psychosocial and professional characteristics of burnout in Swiss primary care practitioners: a cross-sectional survey. Swiss Med Wkly 2005; 135:101-8.

13. Arigoni F, Bovier PA, Sappino AP. Trend of burnout among Swiss doctors. Swiss Med Wkly 2010;140:w13070.

14. Spickard A Jr, Gabbe SG, Christensen JF. Mid-career burnout in generalist and specialist physicians. JAMA 2002;288:1447-50.

15. Web page. Médicos reivindicam progressão na carreira. http://www. asemana.publ.cv/spip.php?article34856

16. Maslach C, Jackson S. MBI-Human Services Survey. http://www. mindgarden.com/products/mbi.htm

17. World Health Organisation. European Health For All Database. 2010 http://data.euro.who.int/hfadb/

18. Web page. Portugal: The Healthcare System. http://www.uemo.eu/ gp-in-europe/86-portugal.html

19. Web page. General Practitioners in the UK. http://www.rxpgonline. com/article1292.html 